\title{
A LEI 13.874/2019 E A PERDA DE UMA CHANCE EM PROL DOS CONTRATOS INTERNACIONAIS: BRASIL, UM DIA TEU FUTURO CHEGARÁ?
}

\section{ARTIGO ORIGINAL}

OLIVEIRA, Rosa Malena Gehlen Peixoto de ${ }^{1}$

OLIVEIRA, Rosa Malena Gehlen Peixoto de. A lei 13.874/2019 e a perda de uma chance em prol dos contratos internacionais: Brasil, um dia teu futuro chegará?. Revista Científica Multidisciplinar Núcleo do Conhecimento. Ano 06, Ed. 07, Vol. 03, pp. 51-76. Julho de 2021. ISSN: 2448-0959, Link de acesso: https://www.nucleodoconhecimento.com.br/lei/contratos-internacionais, DOI: 10.32749/nucleodoconhecimento.com.br/lei/contratos-internacionais

\section{RESUMO}

Este artigo tem por objetivo, a partir de uma pesquisa explicativa, analisar a restrição imposta pelo vigente art. 9ำ, da LINDB, que desde 1942 limita o exercício da autonomia da partes no tocante à escolha do direito aplicável aos contratos internacionais, disposição esta que não apenas se encontra dissonante dos princípios que regem o Direito Internacional Privado contemporâneo, como igualmente não se justifica frente aos ditames constitucionais previstos pela atual Constituição da República, que instituiu o Estado Democrático de Direito. Analisarse-á que a Lei 13.874/2019, que promoveu a Declaração da Liberdade Econômica, perdeu uma valorosa oportunidade de corrigir este descompasso legislativo, malgrado tratar-se de um assunto imprescindível nas dinâmicas negociais, a permitir o incremento, desde já, da participação do Brasil no âmbito do mercado internacional e a favorecer o desenvolvimento socioeconômico nacional.

Palavras-chaves: Escolha do Direito Aplicável, segurança jurídica, contratos internacionais, liberdade contratual, Lei 13.874/2019.

\section{INTRODUÇÃO}

Quem nunca ouviu dizer que o Brasil é o país do futuro[2]?

Conforme dados divulgados em outubro de 2020 e revisados em janeiro de 2021 pelo Fundo Monetário Internacional (FMI), por meio do World Economic Outlook, o Brasil ocupa atualmente a $12^{a}$ posição entre as maiores economias mundiais,

\footnotetext{
${ }^{1}$ Pós-graduada em Direito Aplicado, pela Escola da Magistratura do Paraná. Pós-graduada em Direito Processo Civil, pela Pontifícia Universidade Católica do Paraná. Pós-graduanda em Direito Empresarial pelo UNICURITIBA.
}

RC: 90594

Disponível em: https://www.nucleodoconhecimento.com.br/lei/contratosinternacionais 
deixando o 9 lugar em que esteve no ano de 2019 após uma acentuada desvalorização cambial aliada à significativa queda das atividades econômicas provocadas pela pandemia da Covid-19. (BALASSIANO; CONSIDERA, 2020).

Um recente estudo divulgado pela Fundação Getúlio Vargas, ademais, noticiou que Brasil registrou o menor percentual de crescimento econômico da década 2011-2020 desde 1900, ficando atrás de $82 \%$ dos demais países do mundo quando se considera a evolução da renda per capita. (CONSIDERA; TRECE, 2021).

Além disso, o Banco Mundial em 2020, através do Relatório Doing Business, pelo qual vários indicadores sobre negócios são avaliados, apontou que o Brasil ocupa a 124aㅡ posição no ranking entre 190 países (THE WORLD BANK GROUP, 2020), de modo que certamente muitos fatores interferem no fluxo das riquezas no Brasil, mas é fácil constatar que os negócios não são estimulados como deveriam.

No âmbito dos negócios jurídicos internacionais, por sua vez, o país, atualmente, ocupa a $27^{\mathfrak{a}}$ posição entre as maiores nações exportadoras e a $28^{\underline{a}}$ entre as importadoras, alocando-se especificamente entre os exportadores de produtos manufaturados na $34^{\text {a }}$ posição e entre os exportadores de serviço na $32^{2}$, segundo consta do último Relatório World Trade Statistical Review 2020, da Organização Mundial do Comércio (OMC). (INSTITUTO DE ESTUDOS PARA O DESENVOLVIMENTO INDUSTRIAL (IEDI), 2021; COMEX DO BRASIL, 2021).

Nesta toada, a Organização para a Cooperação e Desenvolvimento Econômico (OECD), num estudo realizado em 2017, pontuou a inexpressividade da participação do Brasil no mercado mundial, pois constatou que: "O Brasil tem potencial para aumentar significativamente seus fluxos comerciais, mas exigirá novos esforços para facilitar e promover o comércio internacional" (OECD, 2017, p.24).

Os especialistas em comércio exterior apontam para uma gama de fatores que justificam essa inexpressividade.

Segundo um estudo de 2018 realizado em parceria pela Fundação Getúlio Vargas e a Confederação Nacional das Indústrias, que se pautou numa pesquisa feita com 589 empresas nacionais, revelou que as maiores dificuldades estão relacionadas ao excesso de tributação e a complexidade do sistema, à burocracia ao comércio exterior; à baixa disponibilidade de investimentos no setor; aos elevados custos com tarifas de portos, aeroportos e com o transporte doméstico; assim como à existência de leis complexas e conflituosas que geram divergência de interpretação, propiciando, portanto, insegurança jurídica. (CONFEDERAÇÃO NACIONAL DA INDÚSTRIA (CNI), 2018. p.18).

Não há dúvidas da imensidão continental, da forte capacidade produtiva, da diversidade socioambiental, entre outros atributos do qual o Brasil é titular, mas, mesmo assim, está em evidente descompasso, isto é, como disse a OECD (2017, p. 21), "O Brasil é uma das dez maiores economias do mundo, mas o papel que 
desempenha nos mercados internacionais está longe de ser proporcional ao seu tamanho econômico".

No âmbito jurídico, que aqui particularmente interessa, tome-se a insegurança jurídica como fator imprescindível e de merecida atenção.

Pode-se tranquilamente afirmar que a segurança jurídica é um dos valores mais importantes de qualquer ordenamento jurídico. No texto constitucional brasileiro de 1988 encontra-se presente desde 0 art. 1ำ, passando pelo art. 5\%, inciso II e XXXVI, art. 16, 150, inc. III, 195, §6으, espraiando-se, assim, por todo o sistema. (BERNARDES; FERREIRA, 2018, p. 204).

O conceito de segurança jurídica não é restritivo e "em um enfoque objetivo, veda a retroação da lei (...). Em sua perspectiva subjetiva, (...) protege a confiança legítima, procurando preservar fatos pretéritos de eventuais modificações na interpretação jurídica". (BRASIL, STF, 2018).

Isto é:

Seja, porém, qual for o sentido que se possa dar à expressão segurança jurídica, a garantia que ela sugere é a de que, ainda que a vida seja essencialmente mutável, será sempre necessário - no que diz com a ordem jurídica ou com os direitos individuais - que tanto quanto possível, uma parte do hoje seja igual ao ontem ou uma fração do amanhã seja igual ao hoje, de tal sorte que a cadeia do tempo se constitua sempre com esse quid de permanência do velho no novo (COUTO E SILVA, 2017)

A segurança jurídica evidencia, em síntese, a estabilidade e a previsibilidade das relações jurídicas.

Nessa órbita de ideias e sem desprezar as dezenas de outras exigências normativas que largamente contribuem com a sofrível posição do Brasil no ranking do estudo liderado pelo Banco Mundial, a questão da impossibilidade da escolha do direito aplicável no âmbito do contrato internacional pelos contratantes, como impõe o art. 9ำ, caput, da Lei de Introdução ao Código Civil, gera insegurança jurídica e enrobustece o denominado Custo Brasil, o qual tem exigido do empresariado brasileiro cerca de 1,5 trilhões de reais por ano para permitir a realização de seus negócios, o que equivale a $22 \%$ do PIB nacional, conforme divulgado pela Secretaria de Produtividade, Emprego e Competitividade, do Ministério da Economia em parceria com a Federação das Indústrias do Estado do Ceará. (FIEC, 2021, p. 9).

Assim, desde 1942, ano em que entrou em vigor, durante o governo de Getúlio Vargas, a Lei de Introdução ao Código Civil, hoje rebatizada de Lei de Introdução às Normas do Direito Brasileiro, pela Lei 12.376/2000, a autonomia das partes no tocante à possibilidade de escolha do direito aplicável no âmbito dos contratos internacionais, outrora permitida pelo art. 13, do Código Civil de 1916, está restrita. 
Quase oito décadas depois e quatro constituições da república, a redação conferida ao art. 9o, da LINDB, ainda é a mesma e a liberdade das partes permanece latente. Nesta ambiência, evidencia-se que a Lei 13.874/2019, como a lei de declaração da liberdade econômica, perdeu uma valorosa oportunidade de corrigir esta dissonância legal que ao tempo que contribui para a insegurança jurídica também desestimula os negócios internacionais.

$\mathrm{Na}$ atual conjuntura, em que são múltiplas as conexões entre as nações, o Brasil não tem encontrado espaço, razão pela qual a sua participação no mercado externo é inexpressiva. investiga-se neste artigo, portanto, através de uma pesquisa explicativa, a urgente necessidade do resgate da liberdade das partes, a fim de thes facultar o exercício da autonomia da vontade, cujo fundamento encontra-se ancorado no Estado Democrático de Direito inaugurado pela Constituição Federal de 1988 , a permitir que o Brasil seja não somente o país do futuro, como tantas vezes prospectado, mas, sim, o país do presente.

\section{A ESCOLHA DO DIREITO APLICÁVEL NOS CONTRATOS} INTERNACIONAIS COMO FRUTO DA AUTONOMIA DA VONTADE DAS PARTES: MECANISMO DE FORTALECIMENTO DA SEGURANÇA JURÍDICA

Não há dúvidas que quando se fala em contrato internacional o que se vem à mente é: relações jurídicas multifacetadas reguladas por ordenamentos jurídicos sobrepostos, fortemente influenciado por convenções, tratados, acordos e princípios de caráter global, a revelar um ambiente tendente a gerar insegurança jurídica, porque sujeito à múltiplas interpretações.

Strenger (1998 apud ARAÚJO; FREITAS, 2020, p. 466) explica que os contratos internacionais se consubstanciam em:

(...) todas as manifestações bi ou plurilaterais da vontade livre das partes, objetivando relações patrimoniais ou de serviços, cujos elementos sejam vinculantes de dois ou mais sistemas jurídicos extraterritoriais, pela força do domicílio, nacionalidade, sede principal dos negócios, lugar do contrato, lugar da execução, ou qualquer circunstância que exprima um liame indicativo de Direito aplicável.

No Brasil, a insegurança jurídica nos contratos internacionais deflui, sobretudo, do seu ordenamento jurídico, especialmente porque subtrai das partes a possibilidade de exercer a autonomia da vontade, contrariamente à tendência contemporânea mundial, que concentra seus esforços para extirpar essas múltiplas interpretações e incidência de mais de um ordenamento jurídico, a fim de propiciar um ambiente 
contratual internacional juridicamente seguro, mas, sobretudo, previsível. (GLITZ, 2020, p. 13).

Em 1916, a Lei 3.071, que introduziu o antigo Código Civil Brasileiro, continha a seguinte regra prevista no seu artigo 13: "Regulará, salvo estipulação em contrário, quanto à substância e aos efeitos das obrigações, a lei do lugar, onde forem contraídas." (BRASIL, 1916).

Disso se extrai que, a princípio, o legislador conferia às partes, por "estipulação em contrário", a possibilidade de instituir outra lei, que não a brasileira, ainda que o lugar da celebração do contrato fosse o Brasil, dando-Ihes autonomia para deliberaram aquilo que melhor Ihes conviessem.

Entretanto, em 1942, época em que vigorava a Constituição de 1937, sob o denominado Estado Novo[3], regido por ideais fascistas e com concentração de poder no Executivo (BERNADES; FERREIRA, 2018, p.93), adveio o Decreto-Lei 4.657, fruto do Poder Executivo, que instituiu a então denominada Lei de Introdução ao Código Civil.

Justamente diante dos caracteres do regime então em vigor, para o qual foi adotado uma política protecionista com foco na valorização da soberania nacional[4], a Lei de Introdução ao Código Civil trouxe a disposição do art. 9ำ, subtraindo das partes, a partir daquele momento, a possibilidade de eleição do direito a regular o contrato internacional, afinal, assim dispôs: "Para qualificar e reger as obrigações, aplicar-seá a lei do país em que se constituírem" (BRASIL, 1942).

Cumpre observar, de partida, que nem sempre é possível saber exatamente onde o contrato teve sua formação concluída, porque guarda em si, por vezes, um lento processo de formação e em que pese o necessário conhecimento do local de celebração ser significativo no tocante à "determinação da lei aplicável ao contrato e do foro competente, outro ponto importante é o da eficácia da aceitação" (VENTURA, 2010), a qual é tratada de forma diversa pelos ordenamentos jurídicos, como bem lembra Carla Ventura (2010, p. 108):

Há uma distinção entre os sistemas do common law e o romano germânico. No common law, adota-se o modelo da mail box rule, em que a conclusão do contrato tem lugar no momento da expedição. Já no modelo de fonte romana, acatou-se a ideia de que o contrato pode ser considerado como tendo sido celebrado no momento em que procede o conhecimento da aceitação.

Frente a isto, de que por vezes sequer é fácil compreender exatamente o local de sua celebração, é fato que para o ordenamento jurídico brasileiro, em razão do art. 9oㅡㄹ da hoje rebatizada Lei de Introdução das Normas de Direito Brasileiro (LINDB), estipula o princípio do locus regit actum, como elemento dirimente de conexão, de forma que o direito obrigacional em questão será regido pelas normas do direito 
brasileiro, independentemente da vontade das partes. (FARIAS; ROSENVALD, 2017, p. 158)

Emiliano Humberto Della Costa (2005, apud OLIVEIRA, 2017, p. 21) explica que:

Essa postura do Brasil, com certeza, vem sendo levada em conta para a análise do "custo" Brasil nas negociações internacionais, em virtude da incerteza jurídica criada, tendo consequências nefastas ao progresso do comércio internacional [...] Sem dúvida, a incerteza jurídica atual, interfere no progresso das atividades de comércio internacional, prejudicando a evolução do direito internacional privado em nosso país, principalmente pela longevidade da nossa Lei de Introdução ao Código Civil, que mesmo com a atualização do Código Civil, ainda se manteve desatualizada, imprópria e desligada dos modernos avanços da ciência que estuda e soluciona os conflitos de leis.

Convém lembrar que a Lei 9.307 de 1996, que instituiu a arbitragem no Brasil e foi considerada como um grande avanço para a época, minimizou os efeitos do art. 9², da LINDB, pois conferiu às partes a possibilidade de eleger o direito a ser aplicável, como define o parágrafo primeiro, do seu art. $2^{\circ}$, a se ver: "Poderão as partes escolher, livremente, as regras de direito que serão aplicadas na arbitragem, desde que não haja violação aos bons costumes e à ordem pública" (BRASIL, 1996).

Entretanto, malgrado não ser possível refutar peremptoriamente que o art. 9º da LINDB, é norma de direito público, portanto, cogente e de aplicação obrigatória, pois ninguém desconhece que a norma introdutória do Código Civil é "um conjunto de normas sobre normas ou uma norma de sobredireito (lex legum), eis que disciplina as próprias normas jurídicas prevendo a maneira de sua aplicação no tempo e no espaço" (TARTUCE, 2015, p. 1), a possibilidade da escolha do direito aplicável estaria, neste caso, atrelada necessariamente à escolha da arbitragem como meio de solução de eventuais conflitos, o que muitas vezes acaba vinculando as partes, ainda que a revelia, à escolha de meio alternativo à jurisdição estatal[5].

Por isso, uma orientação que se propõe é a seguinte:

(...) importante compreender que "diante de um contrato internacional onde há cláusula de escolha de lei, a questão desta escolha derrogar a regra contida no art. $9^{\circ}$, caput, da LICC, é "extremamente difícil e objeto de debate por parte de nossos doutrinadores, e que não encontra uma resposta na jurisprudência (...) o melhor para um negociador seria procurar, na medida do possível, compatibilizar o contrato com as leis aplicáveis potencialmente, concluindo que "nesta linha de raciocínio, entendemos que o art. 9०, caput, da LICC, como norma de ordem pública, não pode ser afastado pela vontade das partes" (BASSO, 1994, p. 201 apud MOMBACH, 2018, p.130). 
Em outro viés, o novel Código de Processo Civil, introduzido pela Lei 13.105/2015, preceitua no seu art. 25 que: "Não compete à autoridade judiciária brasileira o processamento e o julgamento da ação quando houver cláusula de eleição de foro exclusivo estrangeiro em contrato internacional (...)", reconhecendo a autonomia das partes, portanto, para escolher qual jurisdição estatal pretendem se submeter caso surja um conflito (BRASIL, 2015).

Note-se que, adotando o conceito de Forum Shopping[6], o Código de Processo Civil conferiu às partes a escolha do foro (jurisdição), se nacional ou estrangeiro, mas isso não implica, pelo menos diretamente, a possibilidade de escolha do direito aplicável, de modo que frente à norma impositiva do art. 9º, da LINDB, ainda assim poderão as partes eventualmente estarem afetas à normativa brasileira a depender do entendimento do julgador da jurisdição eleita, mesmo que estrangeiro, porque na análise do caso o julgador poderá, na órbita do seu ordenamento jurídico, concluir que aquele contrato deve, em verdade, ser regulado pelas normas do direito brasileiro, de forma que somente a escolha pelas próprias partes de qual seria o direito aplicável seria apta a afastar situações como esta.

O fato é que no mundo contemporâneo não há mais barreiras entre os países, ao revés, o que existe é um profundo processo de integração (social, cultural, econômico, ambiental, político) como consequência da globalização (RODRIGUES; OLIVEIRA; FREITAS, 2001, p. 98), um caminho sem volta.

Note-se, portanto, como conclui a professora Nádia de Araújo, que:

A situação é especialmente crítica no Brasil, pois conforme dito no começo deste artigo, o país ainda utiliza o critério da época medieval do local da celebração. (...) Essa situação que distancia a legislação interna brasileira das regras adotadas pelos parceiros comerciais do país, em especial Estados Unidos e países europeus, adicionam elementos negativos ao chamado custo Brasil, o custo adicional que as operações com o país suportam em face da dificuldade de optar pela legislação mais adequada ao desejo das partes contratantes. (2014, p. 6)

Por esta razão, o sistema jurídico internacional, sensível às dificuldades que a multiplicidade e a sobreposição de ordenamentos jurídicos implicam, priorizando a segurança jurídica, evoluiu no sentido compreender e difundir como uma diretriz inafastável a liberdade de escolha das partes, a exemplo da Conferência da Haia de Direito Internacional Privado $(\mathrm{HCCH})$, que é uma organização internacional intergovernamental do qual o Brasil faz parte.

Note-se, em primeiro lugar, que:

(...) as convenções que a Conferência da Haia produz não são dirigidas a facilitar as relações entre os Estados, mas sim a vida dos indivíduos, em questões privadas e comerciais, nas 
suas relações transfronteiriças e transações internacionais (LOO, 2007, apud ARAÚJO; RAMOS, 2018, p.4)

Diante disto, importante perceber, que o princípio da autonomia da vontade nos contratos internacionais ganha, cada vez mais, um notório relevo, pois permite que os desideratos contratuais objetivados pelas partes sejam atendidos com a devida e imprescindível previsibilidade em caso de ocorrência de eventuais conflitos, extirpando, assim, inesperadas tormentas interpretativas decorrentes de ordenamentos jurídicos que se sobreponham.

E essa é justamente a tendência mundial, pois, como dito, o processo de profunda integração internacional já sentido como efeito da globalização tende a se fortalecer e a se expandir cada vez mais pelos próximos anos, especialmente em razão da denominada "indústria 4.0"[7].

Em 2005, a HCCH aprovou um acordo sobre a eleição de foro. Em 2006, um time de especialistas escolhidos pela sua Secretaria Permanente iniciou um trabalho, concluído em 2015, que culminou nos Princípios da Haia, concebidos para funcionar como um código internacional em prol dos contratos internacionais, tendo a autonomia das partes como a sua força motriz, inclusive no que tange à escolha do direito aplicável. (GLITZ, 2020, p. 13)

Como bem apontado por Rodas (2015), analisando o Brasil neste cenário:

Os princípios da Haia de 2015 não fizeram mais do que entronizar, definitivamente, o princípio do respeito à autonomia da vontade das partes, já largamente aceito. Ao fazê-lo, realçaram, mais uma vez, o incrível atraso do direito brasileiro.

Não se trata de norma estatal, razão pela qual não é vinculante, no entanto, serve como um relevante arcabouço principiológico para nortear a interpretação dos contratos internacionais, tanto para convocar legisladores para adequar suas legislações internas, quanto para fornecer subsídios aos julgadores.

O Paraguai[8] é exemplo de país que se adequou à atual conjuntura e se inspirou nos Princípios da Haia para promulgar a Lei 5.393/2015, inserindo no seu ordenamento jurídico a livre escolha do direito pelas partes em sede de contrato internacional, senão veja-se:

A exposição de motivos conclui que "tendo atualmente um dos regimes mais obsoletos do mundo em termos de contratos transfronteiriços a legislação paraguaia vai passar, com este novo corpo normativo, a estar na vanguarda e até mesmo a lei pode inspirar outras legislações que eventualmente venham a ser elaboradas no mundo, uma vez que marca roteiro de como podem ser traduzidos em um texto legislativo os Princípios da Haia. É importante dizer que este projeto de lei, no caso de ser aprovado,

RC: 90594

Disponível em: https://www.nucleodoconhecimento.com.br/lei/contratosinternacionais 
terá grande impacto no mundo, ademais de passarmos a ser o país com a legislação mais moderna nesta matéria!" (RODRÍGUEZ, 2016, p. 104)

Esta lei paraguaia, que propicia segurança jurídica nos negócios internacionais, ao lado da sua antecessora Lei Maquila, que incentivou a instalação de indústrias estrangeiras no país (MONSORES; OLIVEIRA, 2020, p. 399), além de demais ajustes na política interna do Paraguai, tem justificado o seu crescimento econômico equilibrado ao longo da última década de 4,5\% ao ano, quase 3 vezes mais que seus vizinhos latino-americanos, de ter contribuído com a redução, quase que pela metade, dos índices de pobreza, e praticamente quintuplicado a renda per capita nos últimos anos (BAKKER; CHEE, 2019).

É por estes resultados concretos, que advém de um ambiente juridicamente seguro em prol dos contratos internacionais, que também a Organização dos Estados Americanos (OEA), almejando um futuro próximo de uniformidade mundial no trato destes negócios jurídicos lançou, em 2020, o Guia Relativo ao Direito Aplicado aos Contratos Comerciais Internacionais nas Américas, para igualmente servir como base para alteração da legislação interna dos países, assim como fonte aos órgãos julgadores, caso se deparem com um contrato internacional, permitindo-lhes melhor compreender os caracteres que Ihes são próprios. (GLITZ, 2020, p. 90).

Desta feita, confrontando-se a atualidade brasileira, diante deste panorama jurídico, em que pese algumas tentativas da legislação interna em dar relevo à autonomia da vontade, como a Lei 9.307/96, o novel art. 25, do CPC, a norma do art. 9ํㅡ, da LINDB, da forma em que se encontra desde 1942, vai de encontro aos interesses comerciais do Brasil e destoa integralmente da atual tendência mundial, contribuindo, desta forma, largamente, com a insegurança jurídica que assola o país, porquanto não permite o exercício da vontade das partes para regular seus interesses, ainda que sejam de ordem manifestamente privada, empobrecendo, como consequência, um campo muito fértil de geração de riquezas.

Não fosse isso, não é possível dizer que o art. 9ํㅡ, da LINDB, encontra-se materialmente agasalhado pelo Texto Maior de 1988, como a seguir se verá.

\section{A AUTONOMIA DA VONTADE E A 13.874/2019: UM GRITO PELA LIBERDADE CONSTITUCIONALMENTE ASSEGURADA}

Ao se analisar o contexto jurídico acima delimitado nota-se que a autonomia da vontade das partes é o fator central da questão, pois o quer que se diga ou que não se diga volta-se sempre a ela.

Quando se analisa o tema contratos internacionais, percebe-se claramente que o direito internacional privado agasalha, com prioridade, a autonomia da vontade permitindo às partes o poder de eleger o direito aplicável ao contrato e, assim,

RC: 90594

Disponível em: https://www.nucleodoconhecimento.com.br/lei/contratosinternacionais 
arrastar a ele tudo que estiver contemplado pela ordem jurídica eleita, seja qual e como for.

Isto significa que:

a autonomia da vontade funciona como verdadeiro elemento de conexão do contrato, atuando como um instrumento de aperfeiçoamento do direito, que resulta na eliminação do conflito de leis que eventualmente poderia surgir. A cláusula também é um indicativo da lei que as partes consideraram mais adaptada às especificidades de sua relação jurídica. (ARAÚJO; FREITAS, 2020, p. 467).

Uma vez eleito o ordenamento jurídico (ou até mesmo a Lex Mercatoria[9]) a vontade das partes encontrará, então, os limites contemplados pela ordem jurídica interna.

Por mais amplo que possa parecer, não se pode perder de vista que o respeito à autonomia da vontade desempenha justificadamente um importante papel no mundo contemporâneo. É o que se lê, por exemplo, do item 210 do Guia da OEA, quando pontua acerca da autonomia da vontade, sustentando que:

A autonomia da vontade é um dos pilares do Direito contratual moderno e goza de um elevado grau de aceitação no Direito internacional privado. A base deste princípio é que os contratantes estão em melhor posição para determinar qual Direito é o mais adequado para reger o seu negócio, ao invés de deixar esta determinação para o julgador, caso surja uma disputa. Ele fortalece a segurança jurídica que é necessária para encorajar transações comerciais e pretende reduzir o intervencionismo estatal em favor da iniciativa privada. (GLITZ, 2020, p. 145)

Isso porque, como dito, o objetivo do direito internacional privado é fortalecer a segurança jurídica para encorajar transações comerciais, o que como, também já visto, tem crescido exponencialmente pelo mundo todo e o Brasil não tem encontrado o seu merecido espaço.

Os dias atuais reclamam uma solução, sem a qual o Brasil ficará cada vez mais alijado da nova conjuntura global que ora se apresenta.

Nesta ótica, o art. 9ํ, da LINDB, que é matéria de ordem pública, tem refutado por décadas o exercício desta vontade, subtraindo das partes a faculdade de eleger o direito aplicável ao contrato.

O que se viu anteriormente são algumas alternativas recentes, seja pelo art. $2^{\circ}$, da lei da arbitragem, seja pelo art. 25 , do CPC, mas estas não são suficientes para 
resolver e tampouco afastar a imperatividade do art. 9을 da LINDB, em que pese dissonante da ordem jurídica constitucional atual.

Isto é. Até o final do séc. XIX, o liberalismo foi um farol para humanidade, os ordenamentos jurídicos amoldaram-se a fim de preservar a liberdade do indivíduo ao tempo que limitaram a atuação estatal, entretanto, esse modelo adotado fortemente após a Revolução Francesa de 1789 revelou-se, com o passar do tempo, como fonte de injustiça social ante uma cruel desigualdade que projetou, razão pela qual passou a ser rejeitado a partir do início século XX. (NOVELINO, 2017, p. 53; LENZA, 2015, p. 72).

Por essa razão, com o agravamento da desigualdade social, decorrente de uma liberdade irrestrita aos indivíduos e pelo total abstencionismo do Estado, surgiu a noção de estado social, o qual foi inaugurado pela Constituição do México de 1917 e pela Constituição de Weimar de 1919 (NOVELINO, 2017, p. 57).

Esta foi a denominada fase contemporânea ou constitucionalismo social, cuja missão foi resgatar a intervenção estatal em prol da garantia do mínimo existencial do indivíduo. Assim:

A fase embrionária do constitucionalismo contemporâneo foi demarcada pela preocupação em alterar ou transformar a realidade socioeconômica das sociedades estatais. Daí se falar em constitucionalismo social, cuja principal característica é a incorporação de declaração de direitos econômicos e sociais (...), com o objetivo de garantir a igualdade material humana. (...) No direito positivo, o constitucionalismo social surge com o advento da constituição mexicana de 1917, embora ainda de forma restrita ao critério de participação estatal na ordem econômica e sem romper o regime capitalista. Logo depois, seguiu-se a Constituição alemã de Weimar (1919) (...). A partir daí, o constitucionalismo social avançou pelo mundo ocidental e chegou até o Brasil, cuja Constituição de 1934 foi fortemente influenciada pela Constituição de Weimar". (BERNARDES; FERREIRA, 2018, p.61-62).

Desta feita, nessa conjuntura, o discurso recorrente:

(...) informa a superação de um modelo de Estado Liberal, essencialmente no início do sec. XX, por um modelo de Estado Social, em que se identifica a funcionalização crescente da autonomia privada à vontade dos poderes públicos, dada à falência do modelo anterior para propiciar desenvolvimento econômico. No novo modelo, identificar-se-ia a opção clara pela atuação estatal na economia, sob diferentes formas, no propósito de ordená-la, conduzila, assumindo para si a responsabilidade por propiciar 0 desenvolvimento do país, inclusive por meio de empresas estatais." (OLIVEIRA in SALOMÃO; CUEVA e FRAZÃO (coords), 2020, p. 185).

RC: 90594

Disponível em: https://www.nucleodoconhecimento.com.br/lei/contratos-

internacionais 
Foi neste panorama histórico-jurídico, fortemente influenciado por valores que enalteciam o nacionalismo e a soberania nacional e que se identificava com a funcionalização da autonomia privada à vontade dos poderes públicos (OLIVEIRA in SALOMÃO; CUEVA e FRAZÃO, 2020, p. 185), justificando, a partir disto e sob a égide da outorgada Constituição Federal de 1937 no "Estado Novo" implantado pelo Getúlio Vargas, a forte regulação do Estado na vida privada, no qual, inclusive, direitos fundamentais foram suspensos e a liberdade, consequentemente, reprimida (LENZA, 2015, p. 136-138), é que adveio, em 1942, a Lei de Introdução ao Código Civil.

É de se perceber, no entanto, que a vigente Constituição Federal de 1988 afasta-se de qualquer modelo estático, pois a atual carta é democrática, é liberal e é também social, consagrando direitos individuais e sociais em todas as suas dimensões, constituindo-se a República Federativa do Brasil em um Estado Democrático de Direito, conforme se lê do seu art. 1ํㅡ, caput, pois:

(...) ganhou força na teoria constitucional a proposta de um Estado Democrático de Direito, que possa encontrar na democracia a solução para administrar as tensões entre liberdade e a igualdade. (...) o Estado Democrático de Direito representa um novo paradigma em face do qual os princípios constitucionais e os direitos fundamentais são contextualizados e recebem uma nova leitura. (FRAZÃO, in SALOMÃO; CUEVA e FRAZÃO (coords), 2020, p. 105).

E não por outra razão, dentro desta seara de compatibilização de valores liberdade e igualdade, sem perder de vista a fraternidade, apregoa-se que a atual Constituição brasileira indicou um modelo econômico à sociedade e ao tempo que permite a livre iniciativa (art. 1으, inc. IV) também invoca os valores sociais do trabalho (art. 1으, inc. IV):

Desta maneira:

\begin{abstract}
Parece claro, então, que a tese da superação definitiva do Estado Liberal pelo Estado Social simplifica, erroneamente a realidade. Pode-se adotar a concepção que a Constituição, ao disciplinar os fatos econômicos, não estabelece um programa único (...). Pode-se, por outro lado, entender que o Texto Constitucional revela sua própria ideologia, o seu projeto econômico (...) em qualquer dos casos, contudo, o complexo conjunto de princípios e normas que integra, na contemporaneidade, invalida a ideia de que as Constituições albergariam um modelo de Estado Social (ou de um Estado Liberal). (OLIVEIRA in SALOMÃO; CUEVA e FRAZÃO (coords), 2020, p. 188)
\end{abstract}

Reconheça-se, assim, que são fundamentos, lado a lado, da República Federativa do Brasil, os valores sociais do trabalho e da livre iniciativa, ex vi do art. 10, inc. IV, e do caput, do art. 170, do Texto Constitucional, de forma que como sustenta Cyrino, 
com tom de bom senso, "deve ser adotado um caminho do meio". (in SALOMÃO; CUEVA e FRAZÃO (coords), 2020, p. 203).

Impossível, portanto, dentro da realidade constitucional atual, inaugurada pela Constituição Federal de 1998, compatibilizar a restrição ao exercício da autonomia das partes, no tocante à escolha do direito a ser aplicável aos contratos internacionais, tal como impõe o art. 9o- da LINDB, com os atuais vetores constitucionais, quando mais se constata a conjuntura história em que foi ditada.

Dentro desta mesma perspectiva, para dar guarida a todos os ditames constitucionais, revelando a importância da efetiva aplicabilidade de cada um deles no ordenamento jurídico pátrio, foi promulgada, em 2019, a Lei 13.874, fruto da conversão da MP 881 de 2019.

Esta lei trouxe calorosas discussões, que motivaram a propositura de quatro ações declaratórias de inconstitucionalidade (ADI).

Se é ou não constitucional, por obviedade caberá ao Supremo Tribunal Federal dizer no julgamento das ADls 6156, 6184, 6217 e 6528.

Mas, uma conclusão que parece incialmente ser inafastável é que se trata, de fato, de uma "norma de reforço"[10].

Parece não haver dúvida que a Lei da Liberdade Econômica visou a soltar algumas amarras que prendem o Brasil a um modelo de Estado que não se demonstra nem exclusivo nem funcional, ao passo que pretendeu atender a comandos constitucionais nunca regulados.

Isso porque é preciso compreender que "excesso de dirigismo social implica esvaziamento da liberdade por incremento do intervencionismo. Exagero na noção de decisionismo liberal implica graves efeitos colaterais aos mais fracos e desigualdade" (CYRINO in SALOMÃO; CUEVA e FRAZÃO (coords), 2020, p. 206).

Então, parece claro que a maior contribuição foi resgatar o vetor liberdade também como uma diretriz estatal (assim como se tem feito, no Brasil, nos últimos anos com a igualdade)[11], a fim de reequilibrar os pesos na balança, por isso Cyrino explica, uma vez mais, que: "de maneira alguma a edição da LLE implicará a transformação do Brasil numa nação liberal ao estilo laissez-faire" mas, "cada cidadão possui, diante da Constituição, uma margem de liberdade qualificada para que possa definir sua própria capacidade de trabalhar e empreender." (in SALOMÃO; CUEVA e FRAZÃO (coords), 2020, p.206).

Não há dúvidas que o Brasil precisa adaptar-se a uma realidade mais consentânea com os demais países, de modo que como se retratou na Conferência da Haia em 2005 e como ainda pontuou Fábio Ulhoa Coelho (2007, p. 7): "Não é um despropósito antever o ressurgimento de princípios e noções, que ao longo do 
século XX pareceram relegados aos capítulos "históricos" (...) de inspiração liberal centrados na autonomia da vontade."

E de fato, a própria Constituição Federal de 1988 não estabeleceu um pêndulo nem em total favor da liberdade nem em total favor da igualdade, o que ela estabeleceu é a compatibilização entre tais valores.

Isso porque o propósito fundamentalista do texto constitucional brasileiro de 1988 parecer ser inequívoco: a construção de uma sociedade que seja ao mesmo tempo livre, justa e igualitária, garantindo-se, para tanto, o desenvolvimento nacional, a erradicação da pobreza e da marginalização, a redução das desigualdades, a fim de promover, ao final, o bem de todos, como claramente se extrai dos objetivos da República no seu art. 3‥ (BRASIL, 1988).

E é nessa ambiência que o princípio da autonomia da vontade, relembrada pela Lei 13.874/2019, emoldura-se no princípio da livre iniciativa, verdadeiro elemento do capitalismo que reclama certas condições para funcionar da forma mais eficiente possível.

Desta maneira:

\begin{abstract}
Pode-se entender a nova lei de liberdade econômica como uma forma de preencher um vácuo legal de prover mais concretude ao princípio da livre iniciativa, além de buscar um maior equilíbrio entre os pesos atribuídos aos princípios constitucionais da ordem econômica. Uma doutrina jurídica que trata o princípio da livre iniciativa sempre com um "sim, mas o princípio da justiça social e ou a valorização do trabalho" é o que deve valer não se encaixa nas necessidades de uma economia moderna, pois gera uma insegurança jurídica incompatível com os incentivos requeridos ao desenvolvimento econômico. O descompasso do mundo jurídico com o mundo econômico, nesse caso, irá sempre ancorar as instituições econômicas do país em um equilíbrio de baixo crescimento, comprometendo o próprio bem-estar social que a primazia do princípio da justiça social busca alcançar. (MATTOS in SALOMÃO; CUEVA e FRAZÃO, 2020, p. 404)
\end{abstract}

Nesta perspectiva, o art. 9², da LINDB, tem figurado há praticamente oito décadas como um condicionante a desfavor da liberdade, de forma que o resgate da autonomia da vontade das partes na escolha do direito aplicável é salutar para dar vazão aos negócios internacionais privados e assim movimentar a economia do país, melhorando toda a cadeia produtiva e multiplicando as fontes de geração de recursos internos.

É compreender, por exemplo, que a empresa e todos os negócios privados que ela realiza são fundamentais não só para o desenvolvimento econômico do país, mas também em favor do desenvolvimento social, pois: 
(...) na complexa economia dos nossos tempos, pelo sucesso da empresa criada por iniciativa do empresário passam a se interessar, direta ou indiretamente, muitas outras pessoas. Se a empresa não prospera, seus empregados têm menor margem para pressionarem por melhorias salarias ou nas condições de trabalho; o atendimento aos consumidores, mesmo cumprindo as obrigações legais do CDC, é mais precário; menos atividades econômicas geram menos impostos, e assim por diante". (COELHO in SALOMÃO; CUEVA e FRAZÃO, 2020, p. 445).

Dito isso, a iniciativa, sem desprezar os demais valores constitucionais, deve ser livre e a autonomia da vontade reconhecida, a incluir a liberdade contratual de escolha do direito aplicável pelas partes em sede de contrato internacional, de modo que o art. 9², da LINDB, não projeta o desiderato previsto pela vigente Constituição, pois restringe, sem qualquer contrapartida, a liberdade das partes.

Infelizmente, apesar do "resgate" da liberdade constitucionalmente assegurada, no art. 2으, inc. I, da Lei 13.874/2019, a regra do art. 9º, da LINDB, foi esquecida pelo legislador, perdendo-se assim uma valorosa oportunidade de corrigir um problema histórico, malgrado se tratar de um assunto urgente e imprescindível nas dinâmicas negociais, porquanto permitiria o incremento, desde já, da participação do Brasil no âmbito do mercado internacional.

Há muito se espera pela importante e necessária reforma do art. 9º, da LINDB, seja de forma abrangente, seja de forma específica.

Em 2004, tramitou o Projeto de Lei do Senado 269/2004, cuja proposta era a edição de uma nova lei de introdução ao código civil, que a revogasse por completo. Este projeto foi antecedido por outro ainda, o Projeto de Lei do Senado 4905/1994 propugnado a partir da rejeição de outro ainda, seu antecessor, o Projeto de Lei do Senado 264/1984. (BRASIL, SENADO, 2004)

Todas estas tentativas, entretanto, foram infrutíferas e os projetos arquivados.

Em 2012, uma vez mais, tramitou no Senado Federal, o Projeto de Lei 281/2012, o qual visou originalmente a aperfeiçoar o Código de Defesa do Consumidor, a fim de incluir a disciplina sobre contratos de consumo, que são uma realidade entre milhões de brasileiros, mas no trâmite legislativo recebeu emenda para adequar igualmente a redação do art. 9 , da LINDB. O Projeto foi votado e aprovado em plenário, razão pela qual foi enviado para a Câmara dos Deputados. O último andamento data de 12 de novembro de 2015. (BRASIL, SENADO, 2012).

Se aprovado pela Câmara dos Deputados, a redação do art. 9, da LINDB, restituirá às partes contratantes a liberdade para estipular o direito que regulará o contrato internacional, a se ver: 
Art. 2․․ O Decreto- Lei 4.657, de 4 de setembro de 1942 (Lei de Introdução às Normas de Direito Brasileiro), passa a vigorar com as seguintes alterações:

"Art. As obrigações, salvo os casos específicos previstos em lei, reger-se-ão pela lei do país em que se constituírem.

$$
\begin{aligned}
& 1^{\circ} \text { (revogado) } \\
& 2^{ㅇ} \text { (revogado) }
\end{aligned}
$$

Art. 9-A. O contrato internacional entre profissionais, empresários e comerciantes, reger-se-á pela lei escolhida pelas partes, devendo esta escolha referir-se à totalidade do contrato e ser efetuada mediante acordo expresso entre as partes. (BRASIL, SENADO, 2012)

Por fim, em 2020, como derradeira tentativa que se tem notícia, novo projeto foi apresentado no Senado, desta feita o PLS 1038/2020, destinado a alterar a redação do art. 9 , da LINDB, para permitir o exercício da autonomia das partes em sede de contrato internacional, corrigindo, desta forma, a distorção jurídica que tanto prejudica as relações comerciais internacionais, além de visar a incluir regulamentação própria para os contratos de consumo internacionais. (BRASIL, SENADO, 2020).

Conquanto a própria Lei 13.879/2019, como a Lei da Liberdade Econômica, poderia ter se desincumbido de adequar o art. 9, da LINDB, tem-se a renovação da tentativa de adaptar o texto normativo aos atuais ditames constitucionais e, assim, restituir às partes a escolha de eleição do direito aplicável aos contratos internacionais privados, assunto este que deve ser a ordem do dia, porque mais do que nunca, momento de extremo abalo econômico, fortemente influenciado pela pandemia da Covid-19, o Brasil precisa permitir que riquezas sejam geradas e garantir ao seu povo um justo e merecido desenvolvimento, quando mais a própria Constituição da República assim determina.

Ao Congresso Nacional dirige-se expectativas pela célere aprovação!

\section{CONCLUSÃO}

Portanto, para que este futuro chegue e o Brasil, de fato, seja o país prospectado, é preciso que se coloque em prática, hoje, os objetivos estabelecidos pelo art. $3^{\circ} \mathrm{e}$ 170, da Constituição Federal, relendo-os de forma construtiva, na estrita perspectiva do Estado Democrático de Direito.

Na mesma medida em que se garante a igualdade é necessário se permitir o exercício da liberdade. Ao se permitir que a empresa seja livre e tenha iniciativa, 
exercendo com autonomia da vontade os negócios jurídicos internacionais privados, adequando-se às exigências de mercado internacional, maior será o desenvolvimento nacional, a geração de riquezas e a real chance de se reduzir a pobreza, contribuindo, ao final, com o bem de todos.

É tempo do Poder Legislativo exercer o papel que lhe cabe, ajustando os mecanismos legais necessários e suficientes para permitir o exercício da autonomia da vontade na seara privada em consonância com o que determina a Constituição Federal em vigor, como é o caso do art. 9od da LINDB; do Poder Judiciário de conviver e respeitar a tomada de decisões contratuais pelas partes, compreendendo a assunção dos riscos e o profissionalismo na arte de empreender e a singularidade, nesta temática, dos contratos internacionais; do Poder Executivo de reduzir sua parcela interventiva nesta seara, priorizando o que deve de fato ser priorizado como coibir abusos regulatórios, propiciar incentivos à indústria nacional, adequar a infraestrutura de transporte.

Ainda está em tempo, porque ninguém duvida e jamais duvidou que o Brasil é um mar de oportunidades a ser explorado, razão pela qual e apesar de tudo sempre foi um dos maiores destinatários de investimento internacional, segundo se constata dos relatórios anualmente divulgados pela Conferência das Nações Unidas para o Comércio e Desenvolvimento (UNCTAD).

Brasil: o país para sempre no futuro ou o país do agora?! Mãos à obra!

\section{REFERÊNCIAS}

ABDALLA, Julia Borges da Costa; CENCl, Elve Miguel. A crise da soberania do estado moderno no contexto da pandemia da covid-19: reflexões no meio do caminho. Revista Brasileira de Direito Internacional. Encontro Virtual. v. 6. n. 2. p. 59 - 75. Jul/Dez. 2020. Disponível em: $<$ https://indexlaw.org/index.php/direitointernacional/article/view/7174>. Acesso em: 11 jun.2021.

ARAÚJO, Nádia de. Uma visão econômica do direito internacional privado: contratos internacionais e autonomia da vontade. In: Luciano Benetti Timm. (org.). Direito e economia no Brasil. 1ed. São Paulo: Editora Atlas S.A., 2014, v. 1, p. 433-444. Disponível em: $<$ https://secureservercdn.net/198.71.233.110/1vo.dd8.myftpupload.com/wpcontent/uploads/2020/10/Uma-visa\%CC\%83o-econo\%CC\%82mica-do-DIPrcontratos-internacionais-e-autonomia-da-vontade_Direito-e-economia-noBrasil_2014.pdf>. Acesso em: 14 jun.2021.

ARAÚJO, Nádia de; FREITAS, Caio Gomes. A observância das cláusulas de eleição de foro no Brasil: O Protocolo de Buenos Aires na Jurisprudência Brasileira. In SCOTTI, Luciana B.; VIEIRA, Luciane Klein. (coords). El derecho internacional 
privado del MERCOSUR: en la práctica de los tribunales internos de los Estados Partes. Asunción: Secretaría del Tribunal Permanente de Revisión del MERCOSUR, 2020.p.465-481. Disponível em: $<$ https://secureservercdn.net/198.71.233.65/1vo.dd8.myftpupload.com/wpcontent/uploads/2021/01/ilovepdf_merged.pdf >. Acesso em: 18 mar.2021.

ARAUJO, Nádia de; RAMOS, André de Carvalho. Introdução à obra coletiva Conferência da Haia de Direito Internacional Privado e seus Impactos na Sociedade - 125 anos (1893-2018). Belo Horizonte: Editora Arraes, 2018. P.1-10. Disponível em: < https://secureservercdn.net/198.71.233.65/1vo.dd8.myftpupload.com/wpcontent/uploads/2021/01/2018_ARAUJO-Nadia-de-RAMOS-

Andre\%CC\%81_Apresentac\% $\%$ CC\%A7a\%CC\%83o_125-anos-HCCH.pdf >. Acesso em: 18 mar.2021

BALASSIANO, Marcel; CONSIDERA, Claudio. Como o Brasil se situa entre as maiores economias do mundo no pós-Covid. In Blog do IBRE-FGV. 12 mar.2021. Não paginado. Disponível em: <https://blogdoibre.fgv.br/posts/como-o-brasil-sesitua-entre-maiores-economias-do-mundo-no-pos-covid>. Acesso em: 11 fev.2021.

BAKKER, Bas; CHE, Natasha. Paraguai busca nova transformação após 15 anos de rápido crescimento. In Blog do Internacional Monetery Fund. 18 jul.2019. Não paginado. Disponível em: <https://www.imf.org/pt/News/Articles/2019/07/18/blogparaguay-seeks-new-transformation-after-15-years-of-rapid-growth>. Acesso em 13 abri.2021.

BERNARDES, Juliano Taveira; FERREIRA, Olavo Augusto Vianna Alves. Direito Constitucional. Tomo I - Teoria da Constituição. 8ª̣.ed. Salvador: JusPodivm, 2018.

BRASIL. Constituição da República Federativa do Brasil de 1988, de 5 de outubro de 1988. Disponível em:

<http://www.planalto.gov.br/ccivil_03/constituicao/constituicao.htm>. Acesso em: 26 abr.2021.

Lei № 3.071, de 1ำ de janeiro de 1916. Código Civil dos Estados

Unidos do Brasil. Rio de Janeiro: Diário Oficial da União. 05 jan. 1916. Disponível em: <http://www.planalto.gov.br/ccivil_03/leis//3071.htm>. Acesso em: 11 fev.2021.

. Decreto 4.657 de 5 de setembro de 1942. Lei de Introdução ao Código Civil. Rio de Janeiro: Diário Oficial da União. 4 set. 1942. Disponível em: <http://www.planalto.gov.br/ccivil_03/decreto-lei/Del4657compilado.htm>. Acesso em: 11 fev.2021.

Lei 9.307 de 23 de setembro de 1996. Dispõe sobre a arbitragem. Brasília: Diário Oficial da União. 24 set.1996. Disponível em: <http://www.planalto.gov.br/ccivil_03/leis/l9307.htm>. Acesso em: 15 jun.2021 
. Lei 12.376 de 30 de dezembro de 2010. Altera a ementa do DecretoLei $\mathbf{n}^{\circ}$ 4.657, de 4 de setembro de 1942. Brasília: Diário Oficial da União. $31 \mathrm{dez}$. 2010. Disponível em: <http://www.planalto.gov.br/ccivil_03/_ato20072010/2010/lei/l12376.htm >. Acesso em: 17 fev.2021.

. Lei 13.105 de 16 de março de 2015. Código de Processo Civil. Brasília: Diário Oficial da União. 17 mar. 2015. <http://www.planalto.gov.br/ccivil_03/_ato2015-2018/2015/lei//13105.htm>. Acesso em: 15 jun.2021.

. Lei 13.874 de 20 de setembro de 2019. Institui a Declaração de Direitos de Liberdade Econômica. Brasília: Diário Oficial da União. 20 set. 2019. Disponível em: <http://www.planalto.gov.br/ccivil_03/_ato20192022/2019/lei/L13874.htm>. Acesso em: 17 fev.2021.

Senado Federal. Projeto de Lei 269 de 16 de setembro de 2004. Dispõe sobre a aplicação das normas jurídicas. Brasília: 2004. Disponível em: $<$ https://www25.senado.leg.br/web/atividade/materias/-/materia/70201 >. Acesso em 17 jun.2021.

Senado Federal. Projeto de Lei 281 de 02 de agosto de 2012. Altera a Lei no 8.078, de 11 de setembro de 1990 (Código de Defesa do Consumidor), para aperfeiçoar as disposições gerais do Capítulo I do Título I e dispor sobre o comércio eletrônico, e o art. 9ㅇ do Decreto-Lei no 4.657, de 4 de setembro de 1942 (Lei de Introdução às Normas do Direito Brasileiro), para aperfeiçoar a disciplina dos contratos internacionais comerciais e de consumo e dispor sobre as obrigações extracontratuais. Disponível em:

$<$ https://www25.senado.leg.br/web/atividade/materias/-/materia/106768>.Acesso em 17 jun.2021.

. Senado Federal. Projeto de Lei 1038 de 27 de março de 2020. Altera o art. 9 do Decreto-Lei no 4.657, de 4 de setembro de 1942 (Lei de Introdução às normas do Direito Brasileiro), para introduzir a adoção integral do princípio da autonomia da vontade nos contratos internacionais. Disponível em: https://www25.senado.leg.br/web/atividade/materias/-/materia/141234. Acesso em 17 jun.2021.

Supremo Tribunal Federal (STF). Ag Reg no RE 861.595-MT. 1a Turma. Rel. Min. Luis Roberto Barroso. J. 27.04.2018. DJe 22 mai. 2018. Disponível em: <http://stf.jus.br/portal/diarioJustica/verDiarioProcesso.asp?numDj=99\&dataPublicac aoDj $=22 / 05 / 2018$ incidente $=5033410 \&$ codCapitul $0=5 \&$ numMateria $=73 \&$ codMateria $=$ 2>.Acesso em: 23 abr.2021.

Superior Tribunal de Justiça (STJ). CC 139.519-RJ. 1a sessão. Rel.p/acórdão. Mina.Regina Helena Costa, j. 11.10.2017, DJe 10 nov.2017 
Disponível em: <https://www.stj.jus.br/docs_internet/revista/eletronica/stj-revistaeletronica-2018_249_1_capPrimeiraSecao.pdf>. Acesso em: 17 jun.2021.

Superior Tribunal de Justiça (STJ). Seminário declaração de direitos de liberdade econômica. Debates sobre a MP 881/2019. Brasília: Superior Tribunal de Justiça, 2019. Disponível em:

<https://www.youtube.com/watch?v=29URVVZZ38k\&t=330s>. Acesso em: 18 mar.2021.

COELHO, Fábio Ulhoa. Curso de direito comercial. vol.1. 11 $1^{\text {a }}$ ed. São Paulo: Saraiva, 2007.

COELHO, Fábio Ulhoa. Princípios constitucionais na Interpretação das normas de direito comercial. In SALOMÃO, Luis Felipe; CUEVA, Ricardo Villas Bôas; FRAZÃO, Ana. (Coords). Lei de liberdade econômica e seus impactos no direito brasileiro. 1ª . ed. São Paulo: Thomson Reuters Brasil, 2020. p. 431-450. Vários autores.

COMEX DO BRASIL. Brasil tem participação marginal no comércio mundial de serviços com apenas $0,6 \%$ do total das transações. Brasília, 2021 . Não paginado. Disponível em: <https://www.comexdobrasil.com/brasil-tem-participacaomarginal-no-comercio-mundial-de-servicos-com-apenas-06-do-total-dastransacoes/>. Acesso em: 14 jun.2021

CONFEDERÇÃO NACIONAL DAS INDÚSTRIAS (CNI). Desafios à competitividade das exportações brasileiras. Brasília: CNI, 2018. Disponível em: $<$ http://www.portaldaindustria.com.br/cni/canais/assuntos-

internacionais/publicacoes/desafios-a-competitividade-das-exportacoes-brasileiras/>. Acesso em: 14 jun.2021

CONSIDERA, Claudio; TRECE, Juliana. A nova década perdida brasileira e o resto do mundo - resultados per capita. In Blog do IBRE-FGV. Rio de Janeiro, 12 mar.2021. Não paginado. Disponível em:< https://blogdoibre.fgv.br/posts/novadecada-perdida-brasileira-e-o-resto-do-mundo-resultados-capita>. Acesso em: 07 abr.2021.

COUTO E SILVA, Almiro. Princípio da segurança jurídica no direito administrativo brasileiro. Enciclopédia jurídica da PUC-SP. CAMPILONGO, Celso Fernandes; GONZAGA, Álvaro de Azevedo; FREIRE, André Luiz (Coords.). Tomo: Direito Administrativo e Constitucional. Vidal Serrano Nunes Jr., Maurício Zockun, Carolina Zancaner Zockun; André Luiz Freire (coords. de tomo). 1. ed. São Paulo: Pontifícia Universidade Católica de São Paulo, 2017. Não paginado. Disponível em: $<$ https://enciclopediajuridica.pucsp.br/verbete/17/edicao-1/principio-da-segurancajuridica-no-direito-administrativo-brasileiro>. Acesso em: 24 fev.2021. 
CYRINO, André. A constituição econômica e a Lei no 13.874/2019. In SALOMÃO, Luis Felipe; CUEVA, Ricardo Villas Bôas; FRAZÃO, Ana. (coords). Lei de liberdade econômica e seus impactos no direito brasileiro. São Paulo: Thomson Reuters Brasil, 2020. p.198-210. Vários autores.

DIDIER JR, Fredie. Curso de direito processual civil: introdução ao direito processual civil, parte geral e processo de conhecimento.20.ed. Salvador: JusPodivm, 2018.

FARIAS, Cristiano Chaves de; ROSENVALD, Nelson. Curso de direito civil. Parte geral e LINDB.15.ed.rev.,ampl., e atual. Salvador: JusPodivm, 2017

FIEC - FEDERAÇÃO DAS INDÚSTRIAS DO ESTADO DO CEARÁ. Guia de Elaboração de Proposições do Projeto Redução do Custo Brasil. Fortaleza: FIEC, 2021. Disponível em: <https://www.gov.br/produtividade-e-comercioexterior/pt-br/assuntos/reducao-do-custo-brasil>. Acesso em: 11 jun.2021.

FRAZÃO, Ana. Liberdade econômica pra quem? A necessária vinculação entre a liberdade de iniciativa e a justiça social. In SALOMÃO, Luis Felipe; CUEVA, Ricardo Villas Bôas; FRAZÃO, Ana. (coords). Lei de liberdade econômica e seus impactos no direito brasileiro. São Paulo: Thomson Reuters Brasil, 2020. p.89121. Vários autores.

FURTADO, João et al. Indústria 4.0: A Quarta Revolução Industrial e os Desafios para o Brasil. In A indústria do futuro no Brasil e no mundo. ALMEIDA, Julio Sergio Gomes; Cagnin, Rafael Fagundes (coords). São Paulo: IEDI - Instituto de Estudos para o Desenvolvimento Industrial: 2019. p. 171 - 197. Disponível em: $<$ https://iedi.org.br/media/site/artigos/20190311_industria_do_futuro_no_brasil_e_no mundo.pdf>. Acesso em: 14 jun.2021

GLITZ, Frederico Eduardo Zenedin. Contratos internacionais e a escolha do direito aplicável: tradução dos Princípios Haia e Guia da Organização dos Estados Americanos (OEA) [recurso eletrônico]. Curitiba, 2020. Disponível em: $<$ https://fredericoglitz.adv.br/2020/02/05/contratos-internacionais-e-a-escolha-dodireito-aplicavel-traducao-dos-principios-haia-e-guia-da-organizacao-dos-estadosamericanos-oea/>. Acesso em: 16 fev.2021.

IEDI - INSTITUTO DE ESTUDOS PARA O DESENVOLVIMENTO INDUSTRIAL. Exportações de manufaturados: Brasil em rota declinante. Carta IEDI 1058. São Paulo: 2021. Não paginado. Disponível em: <https://www.iedi.org.br/cartas/carta_iedi_n_1058.html>. Acesso em: 14 jun.2021.

LENZA, Pedro. Direito constitucional esquematizado. 19aㅗ ed. São Paulo: Saraiva, 2015. 
MATTOS, César. A nova lei de liberdade econômica e o bem-estar social no Brasil. In SALOMÃO, Luis Felipe; CUEVA, Ricardo Villas Bôas; FRAZÃO, Ana. (coords). Lei de liberdade econômica e seus impactos no direito brasileiro. São Paulo: Thomson Reuters Brasil, 2020. p.395-412. Vários autores.

MOMBACH, Matheus Martins Costa. Considerações sobre a escolha do direito material aplicável ao mérito do litígio na arbitragem internacional e o papel do árbitro. Revista Digital Constituição e Garantia de Direitos. vol. 11, no 1. p. 121 141, 16 nov. 2018. Disponível em:

<https://periodicos.ufrn.br/constituicaoegarantiadedireitos/article/view/15389>. Acesso em: 14 jun.2021

MONSORES; Carla de Oliveira; OLIVEIRA, Gilson Batista de. Lei de Maquila e a atração de empresas brasileiras para o Paraguai. in Revista Brasileira de Planejamento e Desenvolvimento. Curitiba, v. 9, n. 3, p. 396-424, set./dez. 2020. Disponível em: <https://periodicos.utfpr.edu.br/rbpd/article/view/10524>. Acesso em: 17 jun.2021.

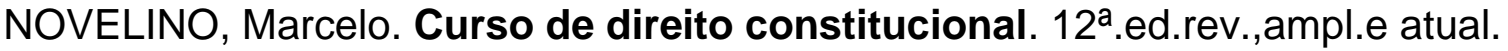
Salvador: JusPodvm, 2017.

OECD - ORGANIZATION FOR ECONOMIC CO-OPERATION AND DEVELOPMENT (OECD). Secretaria das Relações Glogais. Trabalhando com o Brasil 2017.

mar.2018. Disponível em: <https://www.oecd.org/latin-america/Active-with-BrazilPort.pdf>. Acesso em: 30 mar.2021.

OLIVEIRA, Amanda Flávio de. Lei de liberdade econômica: apontamentos acerca da constitucionalidade material da Lei 12.874/2019. In SALOMÃO, Luis Felipe; CUEVA, Ricardo Villas Bôas; FRAZÃO, Ana. (coords). Lei de liberdade econômica e seus impactos no direito brasileiro. São Paulo: Thomson Reuters Brasil, 2020. p.181210. Vários autores.

OLIVEIRA, Camila Andressa Camilo de. Os contratos internacionais e a lex mercatoria. Dissertação em Ciências Jurídico-Empresariais-Menção em Direito Empresarial. Universidade de Coimbra, 2017. Disponível em:

<https://eg.uc.pt/bitstream/10316/84047/1/Disserta\%C3\%A7\%C3\%A3o-CamilaLex\%20Mercatoria\%20e\%20contratos\%20internacionais\%20.pdf.> Acesso em: 08 abr.2021.

RODAS, João Grandino. Princípios da Haia evidenciam insegurança brasileira em contratos internacionais. Revista Consultor Jurídico. 11 jun.2015. Não paginado. Disponível em: <https://www.conjur.com.br/2016-jan-21/olhar-economicojurisdicao-civil-prisma-estraneidade-globalizacao>. Acesso em: 15 jun.2021.

RODRÍGUEZ, José Antonio Moreno. A arbitragem internacional e a nova lei paraguaia de contratos internacionais. Tribunal Permanente de Revisao do 
MERCOSUL. Año 4, 07; Mayo 2016.p. 97-126. Disponível em: $<$ https://www.researchgate.net/publication/303555947_A_arbitragem_internacional_e a_nova_lei_paraguaia_de_contratos_internacionais.> Acesso em: 10 jun.2021.

RODRIGUES, Ana Maria da Silva; OLIVEIRA, Cristina M. V. Camilo de; FREITAS, Maria Cristina Vieira de. Globalização, cultura e sociedade da informação. Perspect. cienc. inf., Belo Horizonte, v. 6, n. 1, p.97-105, jan./jun.2001. Disponível em:

<http://www.ufrgs.br/laviecs/edu02022/portifolios_educacionais/t_20061_m/Leandro Raizer/globalizacao_e_cultura.pdf.> Acesso em: 11 jun.2021.

SEIXAS, Jacy Alves de. Brasil, país do futuro: políticas do esquecimento e imagens identitárias da denegação. Revista de Ciências Sociais Humanas.v.25.n.64. set-dez.2015.p.161-178. Disponível em:

$<$ https://www.metodista.br/revistas/revistasunimep/index.php/impulso/article/view/2835/1683>. Acesso em: 11 mar.2021.

TARTUCE, Flávio. Direito civil: Lei de introdução e parte geral. 11.ed. Rio de Janeiro: Forense; São Paulo: Método, 2015.

THE WORLD BANK GROUP. Doing Business 2020. Comparing Business Regulation in 190 economies. Disponível em:

$<$ https://portugues.doingbusiness.org/pt/data/exploreeconomies/brazil\#>. Acesso em: 14 jun.2021

VENTURA, Carla A. Arena. A Negociação à Formação dos Contratos Internacionais do Comércio: Especificidades do Contrato de Compra e Venda Internacional. Revista Eletrônica de Direito Internacional. vol.6. 2010, p.91-121. Disponível em: <http://www.eerp.usp.br/media/wcms/files/carla ventura.pdf $>$. Acesso em 22 fev.2021.

\section{APÊNDICE - REFERÊNCIA DE NOTA DE RODAPÉ}

2. Muito interessante o resgate histórico realizado pela Profa. Dra. Jacy Alves de Seixas ao analisar criticamente o livro do austríaco Stefan Zweig, escrito em 1941, dos relatos de Robert Southey, datado de 1810; de D. Pedro I, a bordo do Nau Warspite, em 1831; e de Theodore Roosevelt, em 1913, pelos quais todos profetizavam, maravilhados, o Brasil como o país do futuro. (SEIXAS, 2015, p.168).

3. “(...) em 10 de novembro de 1937, Getúlio Vargas dá o golpe ditatorial centralizando o poder e fechando o Congresso Nacional (...) instalando a ditadura ("Estado Novo"), que só teria fim com a redemocratização pelo texto de 1945." (LENZA, 2015, p. 136). 
4. "Este novo Estado firmado em um conceito de soberania que viria a ser reconhecido como absoluta foi, durante séculos, o sujeito exclusivo do Direito Internacional. Naquele momento, o cenário do Direito Internacional era composto por entes independentes entre si, que se reconheciam reciprocamente como soberanos, e por estes motivos, pautavam suas ações internas segundo seus próprios interesses". (ABDALLA; CENCI, 2020, p. 63-64)

5. Está consolidado no STJ que a arbitragem tem natureza jurisdicional (BRASIL, STJ, 2017)

6. O Forum Shopping, segundo Jatahy (2003 apud DIDIER Jr., 2018, p.37) "deixa ao arbítrio do juízo acionado a possibilidade de recusar a prestação jurisdicional se entender comprovada a existência de outra jurisdição invocada como concorrente e mais adequada para atender aos interesses das partes ou os reclamos da justiça em geral".

7. "O termo Indústria 4.0 é utilizado para denominar o projeto alemão de promover um grande salto de competitividade por meio da aplicação de novas tecnologias no mundo da manufatura. Por meio da Indústria 4.0, a Alemanha tem como objetivo o revigoramento do seu tecido industrial e o fortalecimento das suas exportações de equipamentos e soluções "inteligentes". O conceito encontra, contudo, equivalentes fora do contexto alemão como "Advanced Manufacturing", no caso dos EUA. Estes termos são empregados para descrever um novo paradigma industrial, referente à Quarta Revolução Industrial, decorrente de inovações tecnológicas e novos conceitos de organização da cadeia de valor." (FURTADO et al., 2019. p.172).

8. Como informa o Guia da OEA, no item 47, além do Paraguai, a Argentina, a República Dominicana e o Panamá modificaram, muito recentemente, suas respectivas legislações que regem os contratos internacionais. (GLITZ, 2020, p.108)

9. Para Irineu Strenger a lex mercatoria é "um conjunto de procedimentos que possibilita adequadas soluções para as expectativas do comércio internacional, sem conexões necessárias com os sistemas nacionais e de forma jurídica eficaz". (STRENGER, 1996 apud OLIVEIRA, 2017).

10. Conclusão a que chegou o Ministro Gilmar Mendes, no encerramento do Seminário dedicado aos Debates à MP 881. (BRASIL, STJ, 2019)

11. E tal pensamento parece adequar-se perfeitamente às ideias desenvolvidas pelos jusfilósofos modernos, Ronaldo Dworkin e John Rawls, sintetizadas pela professora Ana Frazão, quando deduz do pensamento deles que: "O que se observa, portanto, a partir das reflexões de Rawls e Dworkin, é que a autonomia não se contenta nem com a liberdade formal do Estado Liberal nem com a igualdade material absoluta inexequível do Estado Social. A autonomia diz respeito essencialmente ao direito de cada um realizar o seu próprio projeto de vida". (in SALOMÃO, CUEVA e FRAZÃO (coords).2020, p. 110). 
Enviado: Abril, 2021.

Aprovado: Julho, 2021. 